\title{
ENHANCEMENT OF GALLIUM PHASE-CHANGE HEAT TRANSFER BY COPPER FOAM AND ULTRASONIC VIBRATION
}

\section{Zirui Xu, Xinyi Li, Cong Niu, Qiuwang Wang, E Ting Ma*}

\author{
Key Laboratory of Thermo-Fluid Science and Engineering, MOE, Xi'an Jiaotong \\ University, Xi'an, Shaanxi 710049, China \\ *Address all correspondence to: Ting Ma, Key Laboratory of Thermo-Fluid Science and \\ Engineering, MOE, Xi'an Jiaotong University, Xi'an, Shaanxi 710049, China; \\ Tel.: +86 29 8266 3222; Fax: +86 29 8266 3502, E-mail: mating715@mail.xjtu.edu.cn
}

Original Manuscript Submitted: 6/5/2019; Final Draft Received: 9/2/2019

\begin{abstract}
In this study, the effects of copper foam and ultrasonic vibration on the melting process of lowmelting gallium in a rectangular vessel were experimentally investigated. The effective thermal conductivity, heating wall temperature, most melting duration, and total melting duration during the gallium's melting process were examined for various heating powers. We found that a portion of the gallium remained solid in the corners of the vessel in the late melting stage, and melting the remaining solid portion accounted for approximately $28 \%$ of the total melting duration of the pure gallium. In our test, the corresponding heating wall temperature rose significantly during this stage, which reduced the usable volume of the vessel. However, by the addition of copper foam and ultrasonic waves the remaining solid portion was greatly reduced, and the heating wall temperature was controlled. The total melting time for the gallium with added copper foam and ultrasonic waves was reduced by $10 \%$ and $17 \%$, respectively, below that for the pure gallium melting process. When heat was added using ultrasonic waves for a long period of the melting process, the temperature of the heating surface was consistently lower than a pure gallium heat regenerator without ultrasonic waves. This would enhance the value of workable condition power for devices.
\end{abstract}

KEY WORDS: copper foam, gallium, liquid metal, phase change, ultrasonic wave

\section{INTRODUCTION}

As electronic technology has advanced, the sizes of electronic components have decreased and their speed and frequency have increased, causing the power and caloric values of their per-unit volume to rise rapidly, especially for submicron or nanoscale-sized chips. However, the normal operating temperature range of electronic devices is approximately $-5^{\circ} \mathrm{C}$ to $65^{\circ} \mathrm{C}$, and the probability of failure of the components increases exponentially with the temperature: in the range of $70^{\circ} \mathrm{C}$ to $80^{\circ} \mathrm{C}$ the reliability of the components decreases by $5 \%$ when the working temperature increases by $1^{\circ} \mathrm{C}$. Consequently (Guo, 2000), the thermal control management of complex high-power electronic components is difficult. In addition, local hot spots caused by uneven power distribution of chips due to the fusion of logic and memory components is becoming a key problem, and significantly reduces the performance and reliability of chips. 


\begin{tabular}{|c|c|c|c|}
\hline \multicolumn{4}{|c|}{ NOMENCLATURE } \\
\hline $\begin{array}{l}A \\
C_{p}\end{array}$ & $\begin{array}{l}\text { cross-sectional area, } \mathrm{m}^{2} \\
\text { specific heat capacity, } \\
\mathrm{kJ} /(\mathrm{kg} \cdot \mathrm{K})\end{array}$ & $\lambda_{\text {eff }}$ & $\begin{array}{l}\text { effective thermal conductivity, } \\
\mathrm{W} / \mathrm{m} \cdot \mathrm{K}\end{array}$ \\
\hline$L_{f}$ & specific latent heat of fusion, & \multicolumn{2}{|c|}{ Greek Symbols } \\
\hline & $\mathrm{kJ} / \mathrm{kg}$ & $\lambda$ & thermal conductivity, \\
\hline$P_{h}$ & heating power, W & & $\mathrm{W} / \mathrm{m} \cdot \mathrm{K}$ \\
\hline $\begin{array}{l}P_{u} \\
Q\end{array}$ & $\begin{array}{l}\text { ultrasonic power, W } \\
\text { heat transfer rate, } \mathrm{J}\end{array}$ & $\rho$ & density, $\mathrm{Kg} / \mathrm{m}^{3}$ \\
\hline$t_{u}$ & running time of ultrasound, s & \multicolumn{2}{|c|}{ Subscripts } \\
\hline$T$ & temperature, ${ }^{\circ} \mathrm{C}$ & $\mathrm{PCM}$ & phase-change material \\
\hline$T_{m}$ & most melting duration, $\mathrm{s}$ & eff & effective \\
\hline$T_{t}$ & total melting duration, $\mathrm{s}$ & $\mathrm{h}$ & hot-side surface \\
\hline$V$ & volume, $\mathrm{m}^{3}$ & $\mathrm{c}$ & cold-side surface \\
\hline
\end{tabular}

One effective cooling method is based on latent heat thermal energy storage, which can store and discharge energy by the phase transition of phase-change materials (PCMs). The technology uses the latent heat of PCMs to absorb heat quickly and extensively during working hours or peak times and discharges the accumulated heat to the environment during nonworking hours or off-peak times (Wang et al., 2019). This can be used to control and regulate the temperatures of high-power electronics. The technology uses PCMs to solve inconsistencies in heat transfer in time and space, raising the efficiency of the heat transfer and greatly reducing the volume and weight of electronic devices. In addition, the phase-change thermal expansion technology based on latent heat storage is approximately isothermal in the heat accumulation process, so it can enforce the temperature uniformity of the cooled surface well, thereby reducing thermal stress. Alawadhi and Amon (2013) demonstrated the effectiveness of a thermal control unit composed of PCM and a thermal conductivity enhancer for portable electronic devices by experimental and numerical analyses. Faraji and Qarnia (2007) numerically studied the thermal performance of a hybrid heat sink composed of PCM used for cooling protruding, substrate-mounted electronic chips. They found an optimal thermal conductivity ratio that could maximize the time taken by the chips to reach the critical temperature.

However, the heat transfer efficiency of the current phase-change heat storage system is too low to meet the requirements of high-power electronic devices. On one hand, the low thermal conductivity of commonly used PCMs severely restricts the thermal conductivity of the phase-change process and reduces the heat transfer performance of the phase-change heat storage system (Tabassum et al., 2018). On the other hand, the weak flow of the working fluid, which restricts the capacity of the convective heat transfer in the phase-change process, results in an inhomogeneous distribution of temperature in the phase-change heat storage system, which may cause overheating in severe cases. Currently, the operating power of electronic devices is increasing with corresponding increases in heat flux density and the need for effective heat dissipation. In particular, instantaneous heat dissipation at the peak of operation is becoming essential because electronic devices generally require a lower and narrower temperature range to work 
normally and stably (Gharbi et al., 2015). Heat dissipation has become one of the main impediments to the further improvement of output power and performance of high-power electronic equipment (Chein and Huang, 2004).

Low-melting metal gallium is a potential PCM with favorable thermophysical features such as high thermal conductivity, high latent heat, and stable performance. Fan et al. (2016) found that low-melting-point metals were suitable for thermal management of electronic devices when the quality requirements of heat sinks were less than the volume requirements. Al Omari et al. (2018) embedded discrete cavities filled with an unencapsulated PCM within a solid gallium block for electronic cooling. Ge and Liu (2013) found that $3.4125 \mathrm{ml}$ of gallium could remain below $45^{\circ} \mathrm{C}$ for 16 mins at $2.832 \mathrm{~W}$ and was expected to be used in smartphones and personal computers. Zhang et al. (2019) analyzed the gallium melting performances with different heating methods, and the results showed that the external surface heating could keep electronic devices at a low operation temperature.

Currently, the method of filling a porous skeleton is generally used to increase the thermal conductivity of the phase-change system. A porous skeleton is a network structure composed of pores that are either sealed or interconnected, which can greatly increase the heat exchange area to improve the equivalent thermal conductivity (de Lemos and Carvalho, 2018). Commonly used porous materials are copper or graphite foam. Mancin et al. (2015) experimentally studied the phase transition properties of copper foam-PCM composites. They found that the addition of copper foam improved the heat transfer performance and temperature uniformity in PCMs. Mills et al. (2006) found that the addition of expanded graphite increased the thermal conductivity of PCMs by 20 to 130 times, and the thermal conductivity of the composite PCMs was anisotropic. Zhao et al. (2010) experimentally studied the thermal properties of metal foam-PCM composites. Their results showed that the heat transfer rate of composite PCMs after adding metal foam was 3 to 10 times that of pure PCMs. Ji et al. (2014) found that embedding graphite foams in a PCM with volume fractions as low as 0.8 to 1.2 vol $\%$ increased the thermal conductivity of the PCM by up to 18 times, with negligible change in the melting temperature. Xiao et al. (2013) prepared PCM-nickel foam and PCM-copper foam composite PCMs using a vacuum impregnation method, and the results showed that the thermal conductivity of the composite PCMs was markedly enhanced. The thermal conductivity of the PCM-nickel foam composite was nearly three times larger than that of pure PCM.

These studies showed that the addition of a highly thermally conductive porous skeleton is an effective passive method for improving the heat exchange performance of paraffin wax. However as an active method, ultrasound is effective in improving the natural convective heat transfer performance (Kuzma-Kichta and Leontiev, 2018). Wong (1969) used the hot-wire method to study the influence mechanism of ultrasound on the natural convective heat transfer of water and methanol. He found that the application of ultrasound increased the convective heat transfer coefficient of natural convection by approximately eight times. Choi and Hong (1991) studied the effect of ultrasound on the melting process of paraffin. Their results showed that the application of ultrasonic waves made melting paraffin significantly more efficient than melting paraffin without ultrasound. An experiment by $\mathrm{Oh}$ et al. (2001) found that the effect of ultrasonic vibrations on heat transfer was very important during the melting process of paraffin. They also indicated that the acoustic streaming, agitation, cavitation, and oscillating fluid motion caused by the ultrasonic vibrations were the prime mechanism in the overall melting process and enhanced the process by as much as 2.5 times compared with natural melting. These studies showed that ultrasound has great potential to improve the convective heat transfer performance of a thermal storage system.

Volume 27, Issue 1, 2020 
To the best of our knowledge, few studies have been conducted using a porous skeleton and ultrasound on the melting phenomenon of low-melting metal gallium, and it is necessary to carry out this work. In this study, low-melting metal gallium was used instead of the traditional PCM, and the low-melting metal phase-change thermal storage system was enhanced by a porous skeleton and ultrasound. We filled a rectangular vessel, $50 \mathrm{~mm} \times 50 \mathrm{~mm} \times 20 \mathrm{~mm}$, with gallium. We then tested copper foam with a porosity of $80 \%$ and a pore size of 20 PPI and an ultrasonic device with a $50 \mathrm{kHz}$ frequency and $30 \mathrm{~W}$ of power. We compared the melting phenomena of the copper foam and ultrasonic applications to those of pure gallium.

\section{EXPERIMENTAL PROCEDURE}

\subsection{Experimental Setup}

Figure 1 shows the phase-change thermal storage experiment system of liquid metal gallium. It comprises a test part and a data acquisition part. The test part included three types of heat regenerators (composed of gallium, composite copper foam-gallium, and gallium with ultrasound), a heating device, and an ultrasonic wave device. The heating device used a ceramic electrical heating sheet of $50 \mathrm{~mm} \times 50 \mathrm{~mm}$ with a rated power of $115 \mathrm{~W}$. We did the phase-change experiment at different heating powers by adjusting the current power of the DC stabilized power supply.

For this experiment, we designed and manufactured a pure gallium heat regenerator and a composite copper foam-gallium heat regenerator; both had dimensions of $70 \mathrm{~mm} \times 70 \mathrm{~mm}$ $\times 25 \mathrm{~mm}$. Insulating cotton wraps were used as adiabatic boundaries during the heating process. Both heat regenerators were filled with gallium. For the gallium, the melting temperature was $29.8^{\circ} \mathrm{C}$, the specific heat was $0.4 \mathrm{~kJ} /(\mathrm{kg} \cdot \mathrm{K})$, the latent heat was $80 \mathrm{~kJ} / \mathrm{kg}$, and the thermal conductivity (phase change) was $29.28 \mathrm{~W} /(\mathrm{m} \cdot \mathrm{K})$ (Yang et al., 2016). In the gallium-copper foam composite heat regenerator, copper foam with a porosity of $80 \%$ and a pore size of 20 PPI was connected to the heating surface by soldering. Gallium was injected into the vessel through a needle, while heating was maintained to make the injected gallium retain the liquid state. Before measurement was carried out, the liquid gallium was resolidified many times, and some liquid gallium was also provided to fill up depressed spots caused by the contraction of the gallium in the solidification process. In the pure gallium heat regenerator, the phase-change heat transfer characteristics were tested with and without ultrasonic vibrations. The ultrasonic equipment comprised mainly an ultrasonic wave power source (i.e., an ultrasound generator) and an ultrasonic wave transducer. The ultrasonic transducer was fastened to the middle surface of the copper plate with special glues.

Five measuring points were arranged inside the heat regenerator, as shown in Fig. 2. Measuring point 0 was located at the center of the heating wall. Measuring points 1,2 , and 3 were at the centers of the sections, which were $10 \mathrm{~mm}, 20 \mathrm{~mm}$, and $30 \mathrm{~mm}$ from the heating surface, respectively. Measuring point 4 was near the left bottom corner, and the distance between the point and all the inner wall surfaces was $5 \mathrm{~mm}$. The thermocouples were fixed with acrylic plastic glazing by glue, and the diameters of thermocouples and holes in the copper foam were $2 \mathrm{~mm}$ and $2.5 \mathrm{~mm}$, respectively, which can avoid contact between thermocouples and copper foam. When the measuring point 3 temperature reached $30^{\circ} \mathrm{C}$, we considered most of the internal gallium as melted, and the processing time was regarded as "most of the melting time" $T_{m}$. When the measuring point 4 temperature reached $30^{\circ} \mathrm{C}$, we considered that the internal gallium of the heat regenerator had completely melted, and we defined the "total melting time" $T_{t}$. 


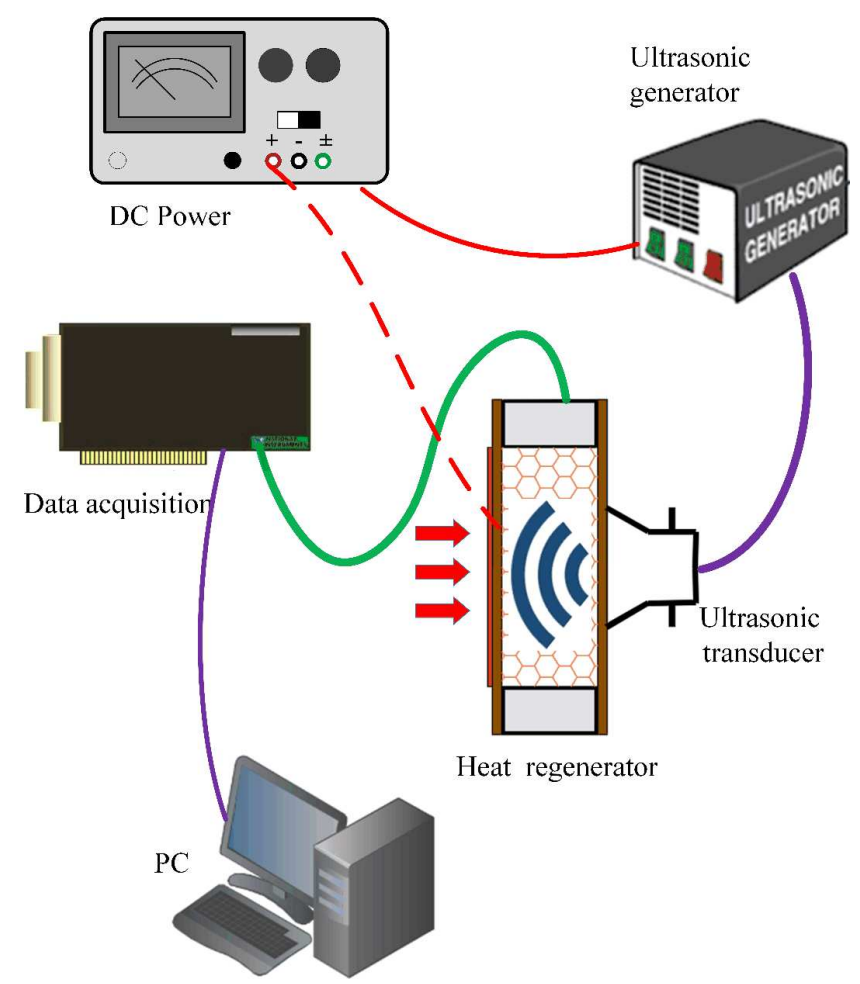

(a)

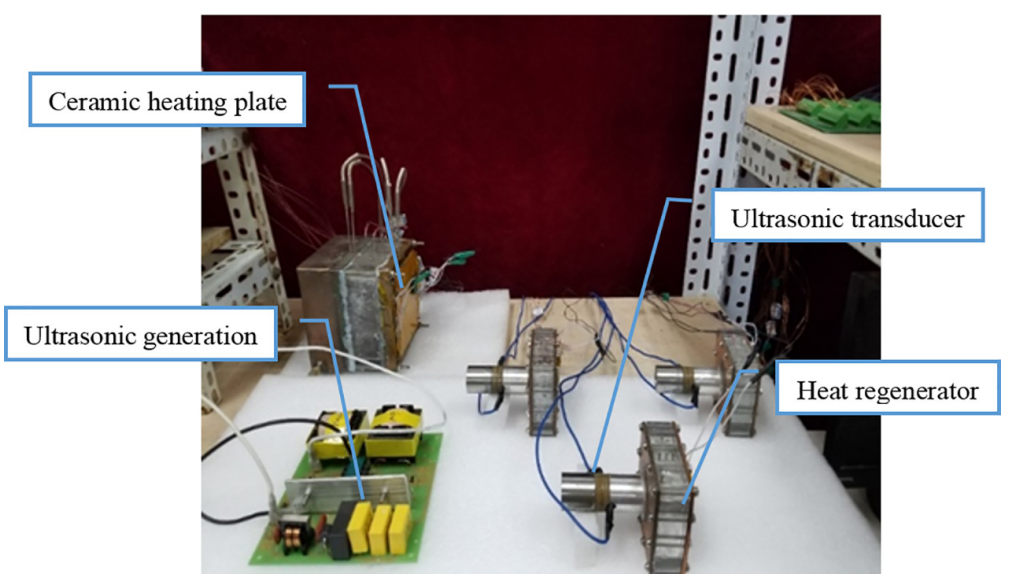

(b)

FIG. 1: Illustration of experimental setup: (a) schematic illustration of experimental setup, (b) image of the experimental apparatus

\subsection{Data Reduction}

The effective thermal conductivity reflected the overall heat transfer capacity of the heat regenerator, and the effective thermal conductivity was formulated as (Xiao et al., 2014) 


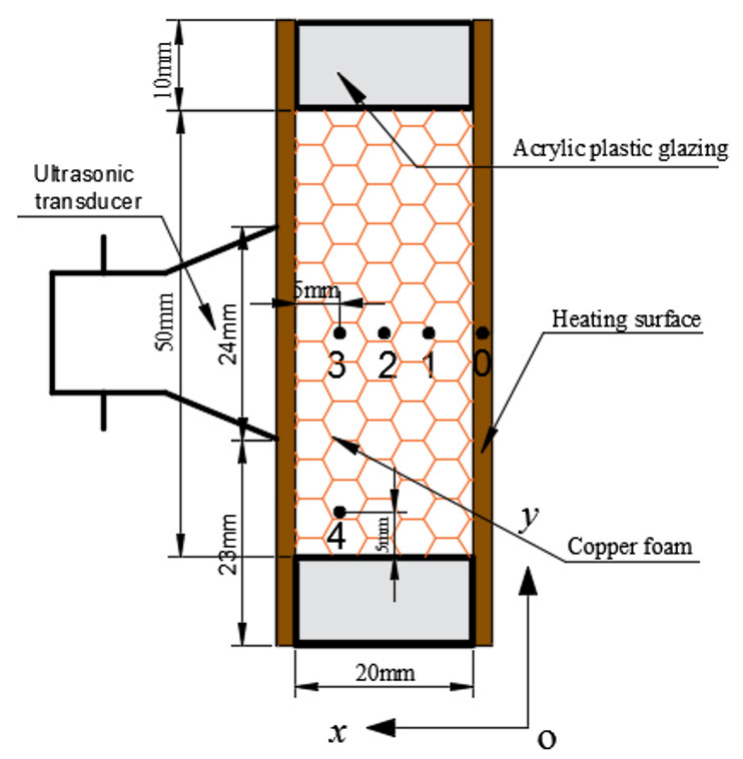

FIG. 2: Schematic diagram of measuring point layout

$$
\lambda_{\text {eff }}=\frac{P_{h} \Delta x_{0,3}}{A \Delta t_{0,3}}
$$

where $\lambda_{\text {eff }}$ is the effective thermal conductivity, $P_{h}$ is the heating power, $\Delta x_{0,3}$ is the distance between point 0 and point 3 , and $\Delta t_{0,3}$ is the temperature difference between point 0 and point 3 .

\subsection{Experimental Uncertainty Analysis}

The uncertainty of the test can be assessed by (Zhao et al., 2010)

$$
R_{t}=\sqrt{\left(\frac{\partial T_{\mathrm{TC}}}{T_{\mathrm{TC}}}\right)^{2}+\left(\partial T_{\mathrm{TDM}} T_{\mathrm{TDM}}\right)^{2}+\left(\frac{\partial q_{\mathrm{PM}}}{q_{\mathrm{PM}}}\right)^{2}}
$$

The overall uncertainty of the temperature measurement $R_{t}$ can be attributed to inaccuracies of measurement for the input heat flux and the temperature, as well as the heat loss. The overall uncertainty of the test was estimated at $7.3 \%$ by using Eq. (2), with $\pm 0.1^{\circ} \mathrm{C}$ for OMEGA thermocouples and $\pm 0.45^{\circ} \mathrm{C}$ for the temperature data measurement tolerance of the Keithley 2700 data acquisition system we used, and the uncertainty of the power meter was $\pm 0.5 \%$.

\section{RESULTS AND DISCUSSION}

\subsection{Comparison of Gallium and Composite Copper Foam-Gallium Heat Regenerators}

The movement of the phase-change interface was the most intuitive way to reflect the phase transition behavior of the phase-change process. Figure 3 shows the trend of the melting interface of the composite copper foam-gallium in a $100 \mathrm{~mm} \times 100 \mathrm{~mm} \times 40 \mathrm{~mm}$ vessel. In the early stage of the melting process, due to the strong thermal conductivity of the copper foam skeleton, heat was 


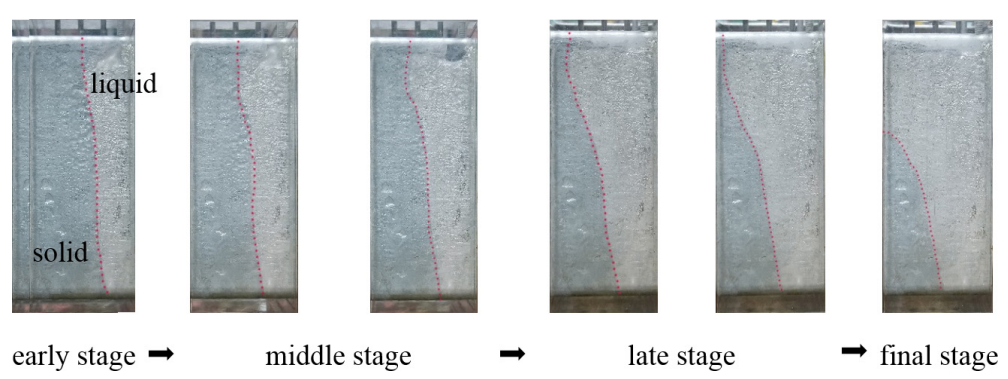

FIG. 3: Melting process of gallium-copper foam composite heat regenerator

transferred to the gallium through the copper foam, and the heat transfer was dominated by heat conduction. The temperature distribution was uniform in the liquid region of the gallium, and the movement of the solid-liquid phase interface was mainly parallel to the heating surface. During the middle and late stages of the melting process, the heat convection phenomenon gradually intensified. The liquid gallium near the heating surface flowed upward due to thermal buoyancy and released heat to melt the contacting solid gallium upward. The cooling liquid gallium flowed back to the bottom along the wall surface of the solid gallium, and the advancing velocity of the upper interface began to be greater than that of the bottom region. In the final stage, a solid gallium buildup formed on the lower left corner of the heat regenerator.

The melting time, heating surface temperature, and temperature distribution of the pure gallium heat regenerators and the composite copper foam-gallium heat regenerators were tested under heating conditions of $1.2 \mathrm{~W} / \mathrm{cm}^{2}, 1.6 \mathrm{~W} / \mathrm{cm}^{2}$, and $2 \mathrm{~W} / \mathrm{cm}^{2}$ respectively.

\subsubsection{W Heating Power}

Figure 4 shows the temperature evolutions of each measuring point in the pure gallium and composite copper foam-gallium heat regenerators under $1.6 \mathrm{~W} / \mathrm{cm}^{2}$ heating power. In the initial stage of the experiment, the temperatures of the four measuring points rose with a large slope, and the heat regenerator was in the sensible heat storage stage. In this stage, the heat

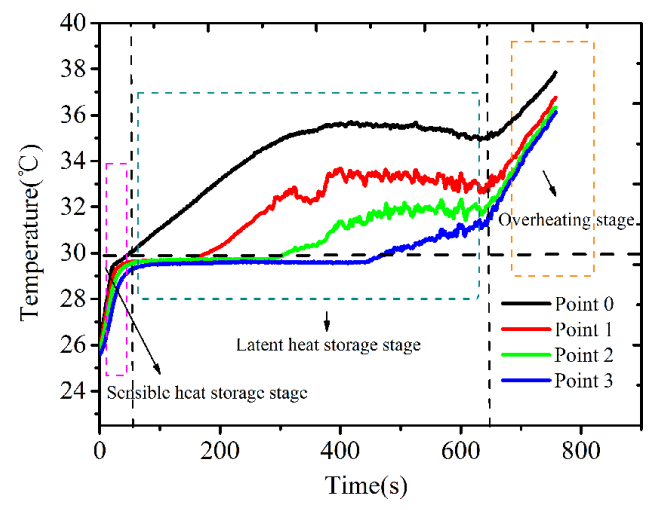

(a)

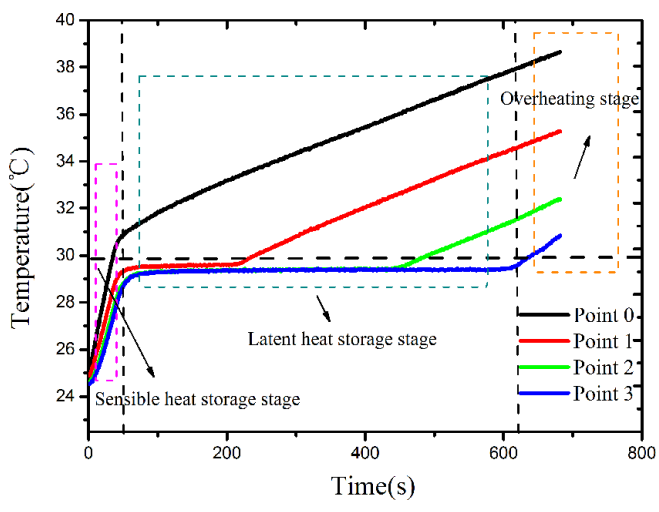

(b)

FIG. 4: Temperature evolution of pure gallium and copper foam-gallium composite heat regenerators with $1.6 \mathrm{~W} / \mathrm{cm}^{2}$ heating power: (a) pure gallium, (b) copper foam-gallium composite 
transfer was dominated by heat conduction, and the temperature inside the heat regenerator was uniform, which showed the strong thermal conductivity of gallium. The stage duration of the composite copper foam-gallium heat regenerator was shortened to $10 \%$ of the stage duration of the pure gallium heat regenerator, which indicates that the addition of copper foam significantly enhanced the overall thermal conductivity of the heat regenerator. The latent heat storage stage lasted for approximately $590 \mathrm{~s}$, which took up most of the heat regenerator's operating time. It can be observed that the trend in the temperature evolutions of the internal measuring points of the pure gallium heat regenerator was increased first with a gradual slope and then maintained for a long time, accounting for almost $38 \%$ of the latent heat storage stage. The reason is that in the early period of the gallium's latent heat storage process, the heat conduction was the main part of the heat transfer. The heat had not been transferred from the melting liquid gallium to the solid gallium completely, so the initial temperature increased as the region of liquid phase increased. The convective heat transfer mode became the main part of the heat transfer with high heat transfer efficiency, so the temperature tended to be consistent. The temperatures inside the composite copper foam-gallium heat regenerator were more regular than those of the pure gallium heat regenerator, the heating surface temperature increased linearly with a gradual slope, and temperatures of the internal measuring points remained basically unchanged during the latent heat storage process of the gallium. In addition, it can be seen that the temperature of measuring points 1,2 , and 3 of the composite copper foam-gallium heat regenerator remained at the melting point of $30^{\circ} \mathrm{C}$, which was lower than that of the pure gallium heat regenerator at the stable stage. This shows that the addition of copper foam greatly increased the uniformity of the internal temperature of the heat regenerator. The flow of the liquid gallium in the copper foam included mainly natural convection and porous medium seepage, in which the natural convection flowed mainly in the $y$-axis direction, and the porous seepage accelerated the flow in the $x$-axis direction. In the latent heat storage stage, the temperature of the internal composite copper foam-gallium heat regenerator increased by a gradual slope, while the pure gallium heat regenerator had a relatively small temperature rise at this stage. The addition of copper foam enhanced the proportion of the thermal conductivity, and the porous skeleton hindered the natural convection in the system, but the overall performance was enhanced. In the overheating stage, the temperature of all points rose markedly.

\subsubsection{Influence of Heating Power on Performance of Heat Regenerator}

Figure 5 compares the heating wall temperatures of the pure gallium and composite copper foam-gallium heat regenerators in $1.2 \mathrm{~W} / \mathrm{cm}^{2}$ and $2 \mathrm{~W} / \mathrm{cm}^{2}$ heating powers. In the initial stage of sensible heat storage, the heat transfer capacity depended on the thermal conductivity of the PCM near the heating wall region, and the porous skeleton had less effect. The heating wall temperatures of the two heat regenerators were almost the same. In the melting process, the heating wall temperature of the composite copper foam-gallium heat regenerator was always slightly higher than that of the pure gallium heat regenerator, and the temperature difference of the heating surface between the two heat regenerators first decreased, then increased, and finally decreased. After the gallium was completely melted, the temperature difference of the heating wall of the two heat regenerators was about $1^{\circ} \mathrm{C}$.

\subsubsection{Comparison of Melting Time}

Figure 3 shows that the temperature distribution in the gallium-copper foam heat regenerator was not uniform during the melting process. Due to the natural convection, the hot gallium 


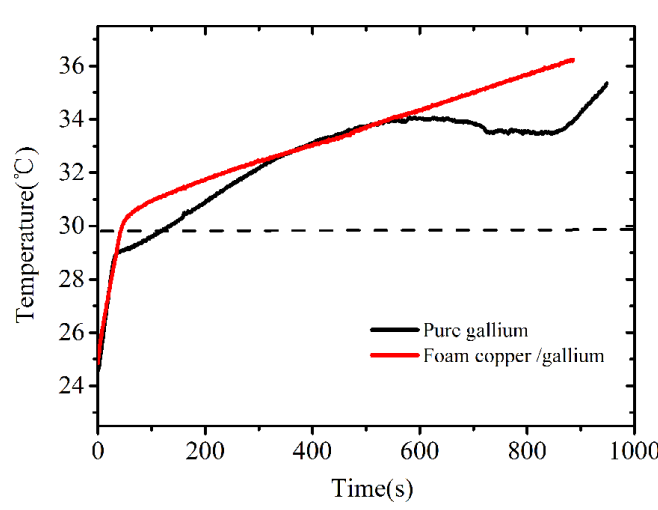

(a)

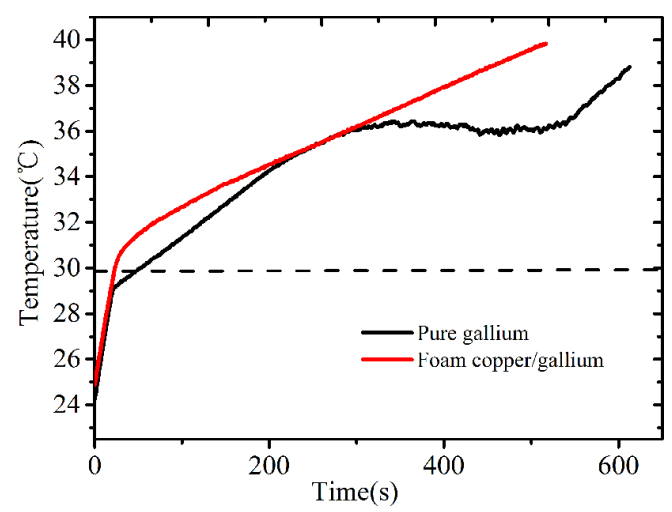

(b)

FIG. 5: Comparison of heating wall temperature between pure gallium and composite copper foam-gallium heat regenerators: (a) $1.2 \mathrm{~W} / \mathrm{cm}^{2}$ heating power, (b) $2 \mathrm{~W} / \mathrm{cm}^{2}$ heating power

flowed upward and the cold gallium regenerator to the bottom. A significant phenomenon is that an accumulation of solid gallium formed in the bottom area of the cold wall at the end of the melting process, and the melting time of this accumulated portion part accounted for a certain proportion of the total melting time. In order to quantitatively analyze the heat transfer performances of the phase-change processes of the different heat regenerators, the melting time of the pure gallium heat regenerator was divided into two parts: the total melting time and most of the melting time. The internal temperature distribution of the composite copper foam-gallium heat regenerator was more uniform, and the values of the two types of time were approximately equal, so we recorded that as the total melting time. As shown in Table 1, the total melting time of the composite copper foam-gallium heat regenerator was approximately $10 \%$ less than that of the pure gallium heat regenerator, and the most melting time of the gallium-copper foam composite heat regenerator was greater than that of the pure gallium heat regenerator. The reason was that the heat was more evenly distributed along the copper foam skeleton into the interior of the heat regenerator.

\subsubsection{Comparison of Effective Thermal Conductivity}

Table 2 shows that the average effective thermal conductivity of the composite copper foamgallium heat regenerator was $46.20 \mathrm{~W} /(\mathrm{m} \cdot \mathrm{K})$, which was about $30 \%$ lower than the average effective thermal conductivity of the pure gallium heat regenerator. The convection flow in copper foam plays an important role in the melting process of gallium. The addition of copper foam

TABLE 1: Melting time of pure gallium and composite copper foam-gallium heat regenerators under various heating powers

\begin{tabular}{|c|c|c|c|c|c|c|}
\hline- & \multicolumn{2}{|c|}{$\mathbf{1 . 2} \mathbf{W} / \mathbf{c m}^{2}$} & \multicolumn{2}{c|}{$\mathbf{1 . 6} \mathbf{~ W} / \mathbf{c m}^{2}$} & \multicolumn{2}{c|}{$\mathbf{2 ~ W / \mathbf { c m } ^ { 2 }}$} \\
\hline- & Gallium & Composite & Gallium & Composite & Gallium & Composite \\
\hline Total time/s & 949 & 887 & 745 & 670 & 614 & 518 \\
\hline Most time/s & 688 & 887 & 565 & 640 & 412 & 518 \\
\hline
\end{tabular}

Volume 27, Issue 1, 2020 
TABLE 2: Comparison of effective thermal conductivity between pure gallium and galliumcopper foam composite heat regenerators at different heating powers

\begin{tabular}{|c|c|c|c|c|c|c|}
\hline- & \multicolumn{2}{|c|}{$\mathbf{1 . 2} \mathbf{W} / \mathbf{c m}^{2}$} & \multicolumn{2}{c|}{$\mathbf{1 . 6 ~ W / \mathbf { c m } ^ { 2 }}$} & \multicolumn{2}{c|}{$\mathbf{2 ~ W / \mathbf { c m } ^ { 2 }}$} \\
\hline- & Gallium & Composite & Gallium & Composite & Gallium & Composite \\
\hline$\lambda_{\text {eff }} / \mathrm{W} /(\mathrm{m} \cdot \mathrm{K})$ & 65.01 & 45.00 & 62.60 & 46.42 & 70.59 & 47.17 \\
\hline
\end{tabular}

improved the thermal conductivity of the gallium, while the convective heat transfer was hindered because of the increase of flow resistance. And as the high porosity and irregularities of copper foam surface, the contact area with the solid surface interface is small. This leads to high values of the thermal contact resistance between the copper foam and the copper heating wall, which affected the overall thermal performance of the heat regenerator.

\subsection{Comparison of Gallium Heat Regenerators with and without Ultrasonic Waves}

For this experiment, the ultrasonic devices with $50 \mathrm{kHz}$ frequency and $30 \mathrm{~W}$ power were chosen. The measuring point arrangement of the ultrasonic heat regenerator was consistent with that of the pure gallium heat regenerator. The temperature of the heating surface, the temperature distribution, and the melting time were compared with those of the pure gallium heat regenerator. To prevent the no-load loss of ultrasonic transducer, ultrasound waves were turned on after a liquid gallium layer had been formed. During the experiment, the ultrasonic generator was turned on when the heating had been conducted for $3 \mathrm{~min}$, and the ultrasonic wave was input along the opposite direction of the heat flow transmission. The phase-change heat storage characteristics were tested at $1.2 \mathrm{~W} / \mathrm{cm}^{2}, 1.6 \mathrm{~W} / \mathrm{cm}^{2}$, and $2 \mathrm{~W} / \mathrm{cm}^{2}$ heating power. Although energy was added by applying ultrasonic waves, the ultrasonic device was considered a separate part in this system. The melting time and the temperature of the heating surface are considered two of the most important indicators of heat regenerators.

\subsubsection{W Heating Power}

As shown in Fig. 6, the temperature evolution trend of the measuring points in the ultrasonic heat regenerator was consistent with that of the pure gallium heat regenerator. It can be seen that the temperature of the heating surface increased slowly, but the temperature differences between the measuring points inside the ultrasonic heat regenerator clearly decreased. During the latent heat storage stage, the temperature difference of the gallium heat regenerators with ultrasonic waves at point 0 was $3.86^{\circ} \mathrm{C}$, which was $6.5 \%$ times less than that of the gallium melting process without ultrasonic waves. After the gallium was completely melted, the temperature of the entire heat regenerator was almost the same, which indicates that the application of the ultrasonic wave enhanced the heat transfer capacity of the heat regenerator. As the liquid phase area increased, the temperature difference between the measuring points decreased to a greater extent with the application of ultrasonic waves.

\subsubsection{Comparison of Heating Wall Temperature}

Figure 7 compares the heating wall temperatures of the gallium and ultrasonic gallium heat regenerators at $1.2 \mathrm{~W} / \mathrm{cm}^{2}$ heating power. The curves omit the overheating stage of the gallium, 


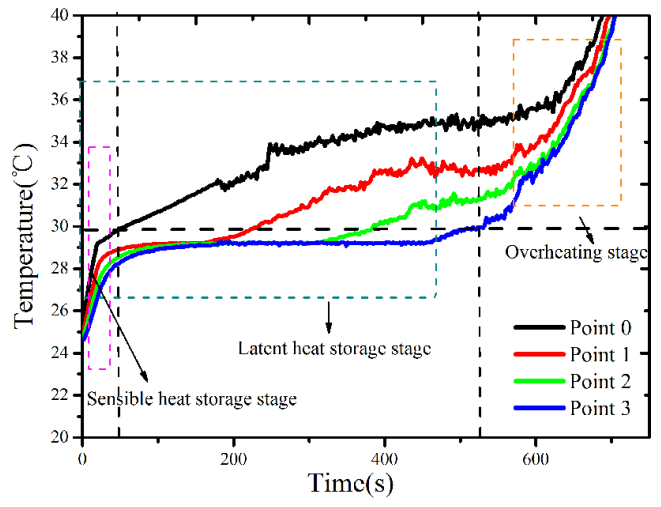

FIG. 6: Temperature evolution of gallium-ultrasonic heat regenerator with $1.6 \mathrm{~W} / \mathrm{cm}^{2}$ heating power

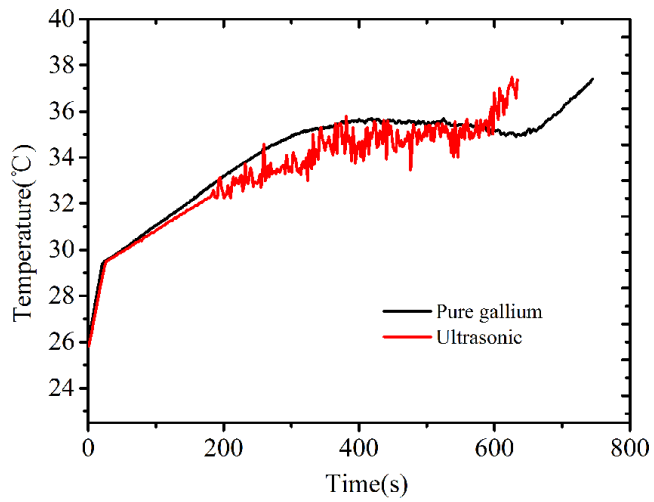

FIG. 7: Comparison of heating wall temperature between pure gallium and gallium-ultrasonic wave heat regenerators at heating power of $1.2 \mathrm{~W} / \mathrm{cm}^{2}$

which is the stage of heat storage. It was found that the temperature of the heating wall was almost the same as that of the pure gallium heat regenerator without ultrasonic waves during the melting process because the ultrasonic wave contributed additional heat.

\subsubsection{Comparison of Melting Time}

As mentioned above, a portion of solid gallium remained in the pure gallium heat regenerator at the end of the melting process due to natural convection, which occurred for approximately $28 \%$ of the total melting time. The melting process of the solid residual gallium could not control the temperature of the heating surface effectively and led to a decrease in heat storage capacity. Figure 8 shows that the volume of the residual solid gallium decreased after the ultrasonic waves were added. The ultrasonic waves enhanced the heat convection as the liquid phase area increased and suppressed the temperature inhomogeneity caused by the natural convection, thus greatly reducing the melting time of the residual gallium. As shown in Table 3, the total melting time of the ultrasonic gallium heat regenerator was $17.2 \%$ less than that of the pure gallium heat regenerator, and the solid stacking time accounted for approximately $18.9 \%$ of the total melting time. The ultrasonic wave promoted the melting speed and enhanced the gallium utilization of the heat regenerator.

Volume 27, Issue 1, 2020 


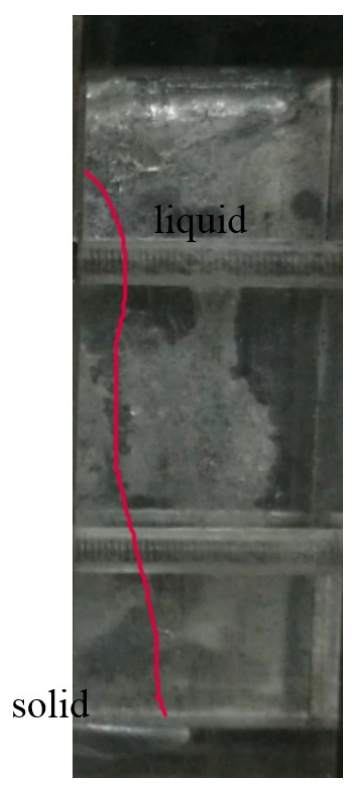

(a)

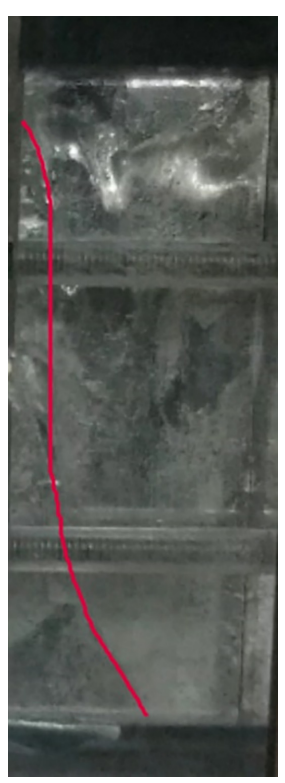

(b)

FIG. 8: Comparison of melting interface between pure gallium and gallium-ultrasonic wave heat regenerators at 90 s before completely melted: (a) pure gallium, (b) ultrasonic waves

TABLE 3: Comparison of melting times and efficiencies between pure gallium and galliumultrasonic heat regenerators under various heating powers

\begin{tabular}{|c|c|c|c|c|c|c|}
\hline- & \multicolumn{2}{|c|}{$1.2 \mathrm{~W} / \mathbf{c m}^{2}$} & \multicolumn{2}{c|}{$\mathbf{1 . 6 ~ W / \mathbf { c m } ^ { 2 }}$} & \multicolumn{2}{c|}{$\mathbf{2 ~ W / \mathbf { c m } ^ { 2 }}$} \\
\hline- & Gallium & Ultrasound & Gallium & Ultrasound & Gallium & Ultrasound \\
\hline Total melting time/s & 949 & 792 & 745 & 634 & 614 & 490 \\
\hline Most melting time/s & 688 & 613 & 565 & 538 & 412 & 397 \\
\hline
\end{tabular}

\section{CONCLUSIONS}

To enhance the heat transfer performance of a heat regenerator, we determined the effects of copper foam and ultrasonic waves on the performance of a gallium heat regenerator by experiments. The main conclusions are as follows.

1. Convective heat transfer is an important phenomenon throughout the entire heat storage process. In the initial stage, the liquid phase area is a relatively small proportion of the total area. The heat and mass transfer between the hot and cold fluids in the heat regenerator are not obvious, and the temperature of the gallium in the liquid region is relatively uniform. As the liquid phase increases, the convective heat transfer plays a greater role, leading to a higher temperature in the upper region of the heat regenerator than that in the lower region, but the temperature difference at the same cross section is small.

2. The temperature distribution of gallium with the addition of copper foam is more uniform than that of the pure gallium heat regenerator. Also, the duration of the sensible heat storage process is significantly reduced. The melting time is about $10 \%$ less than that of 
the pure gallium heat regenerator. In the copper foam regenerator, the temperature difference perpendicular to the heat flow decreases, and the internal temperature of the heat regenerator is more uniform, which is suitable for high-power heat storage conditions.

3. At the end of the melting process, due to the influence of natural convection, a portion of the solid gallium remains in the corners of the pure gallium heat regenerator. The melting time of that portion accounts for approximately $28 \%$ of the total melting time. In this case, the wall temperature rises and the heat storage capacity of the heat regenerator is reduced. The application of ultrasound waves greatly improves the refractory phenomenon. As the area of the liquid phase increases, the enhancement of the convection phenomenon caused by the ultrasonic wave becomes greater. The forced convection of the ultrasonic waves reduces the temperature inhomogeneity caused by natural convection in the heat regenerator, and for a long period of the melting process the temperature of the heating surface is consistently lower than that of the pure gallium heat regenerator without ultrasonic waves. The total melting time is reduced by more than $15 \%$, and the refractory phenomenon of solid gallium in the corners of the regenerator at the end of the melting is effectively shortened by more than $40 \%$, thus enhancing the heat transfer capacity of the heat regenerator.

\section{ACKNOWLEDGMENTS}

This work is supported by the National Natural Science Foundation of China (No. 51676155), the Combined Foundation of the National Natural Science Foundation of China and the Research Grants Council of Hong Kong of China (No. 51861165105), the Foundation for Innovative Research Groups of the National Natural Science Foundation of China (No. 51721004), and the Program of Introducing Talents of Discipline to Universities Project (No. B16038).

\section{REFERENCES}

Alawadhi, E.M. and Amon, C.H., PCM Thermal Control Unit for Portable Electronic Devices: Experimental and Numerical Studies, IEEE Trans. Comp. Packag. Technol., vol. 26, pp. 116-125, 2013.

Al Omari, S.A.B., Ghazal, A.M., and Elnajjar, E., A Novel Concept to Enhance the Applicability of Solid Gallium as Phase Change Material for Heat Sinks by Integrating within It Discretely Distributed Chunks of Un-Encapsulated PCM, Int. Commun. Heat Mass Transf., vol. 91, pp. 274-281, 2018.

Chein, R. and Huang, G.M., Thermoelectric Cooler Application in Electronic Cooling, Appl. Therm. Eng., vol. 24, pp. 2207-2217, 2004.

Choi, K.J. and Hong, J.S., Experimental Study of Enhanced Melting Process under Ultrasonic Influence, J. Thermophys. Heat Transf., vol. 5, pp. 340-346, 1991.

de Lemos, M.J.S. and Carvalho, P.H.S., The Effects of Porosity and Mass-to-Thermal Drive Ratio on Aiding and Opposing Convection in Porous Enclosures, J. Enhanced Heat Transf., vol. 25, pp. 399-419, 2018.

Fan, L.W., Wu, Y.Y., Xiao, Y.Q., Zeng, Y., Zhang, Y.L., and Yu, Z.T., Transient Performance of a Thermal Energy Storage-Based Heat Sink Using a Liquid Metal as the Phase Change Material, Appl. Therm. Eng., vol. 109, pp. 746-750, 2016.

Faraji, M. and EI Qarnia, H., Cooling Management of a Protruding Electronic Components by Using a Phase Change Material Heat Sink, in 14th IEEE Int. Conf. on Electronics, Circuits and Systems, 2007 (ICECS 2007), vol. 174, pp. 11-14, 2007.

Volume 27, Issue 1, 2020 
Ge, H. and Liu, J., Keeping Smartphones Cool with Gallium Phase Change Material, J. Heat Transf., vol. 135, p. 054503, 2013. DOI: 10.1115/1.4023392

Gharbi, S., Harmand, S., and Jabrallah, S.B., Experimental Comparison between Different Configurations of PCM based Heat Sinks for Cooling Electronic Components, Appl. Therm. Eng., vol. 87, pp. 454-462, 2015.

Guo, Z.Y., Frontier of Heat Transfer-Microscale Heat Transfer, Adv. Mechan., vol. 30, pp. 1-6, 2000.

Ji, H., Sellan, D.P., Pettes, M.T., and Kong, X., Enhanced Thermal Conductivity of Phase Change Materials with Ultrathin-Graphite Foams for Thermal Energy Storage, Energy Environ. Sci., vol. 7, pp. 1185-1192, 2014.

Kuzma-Kichta, Y. and Leontiev, A., Choice and Justification of the Heat Transfer Intensification Methods, J. Enhanced Heat Transf., vol. 25, pp. 465-564, 2018.

Mancin, S., Diani, A., Doretti, L., Hooman, K., and Rossetto, L., Experimental Analysis of Phase Change Phenomenon of Paraffin Waxes Embedded in Copper Foams, Int. J. Therm. Sci., vol. 90, pp. 79-89, 2015.

Mills, A., Farid, M., Selman, J.R., and Al-Hallaj, S., Thermal Conductivity Enhancement of Phase Change Materials Using a Graphite Matrix, Appl. Therm. Eng., vol. 26, pp. 1652-1661, 2006.

Oh, Y.K., Park, S.H., and Cha, K.O., An Experimental Study of Accelerating Phase Change Heat Transfer, KSME Int. J., vol. 15, pp. 1882-1891, 2001.

Tabassum, T., Hasan, M., and Begum, L., Thermal Energy Storage through Melting of a Commercial Phase Change Material in a Horizontal Cylindrical Annulus, J. Enhanced Heat Transf., vol. 25, pp. 211- 237, 2018.

Wang, J.F., Xie, H.Q., Guo, Z.X., Cai, L., and Zhang, K., Using Organic Phase-Change Materials for Enhanced Energy Storage in Water Heaters: An Experimental Study, J. Enhanced Heat Transf., vol. 26, pp. 167-178, 2019.

Wong, S.W., Effects of Ultrasonic Vibrations on Heat Transfer to Liquids by Natural Convection and by Boiling, AlChE J., vol. 15, pp. 281-288, 1969.

Xiao, X., Zhang, P., and Li, M., Preparation and Thermal Characterization of Paraffin/Metal Foam Composite Phase Change Material, Appl. Energ., vol. 112, pp. 1357-1366, 2013.

Xiao, X., Zhang, P., and Li, M., Effective Thermal Conductivity of Open-Cell Metal Foams Impregnated with Pure Paraffin for Latent Heat Storage, Int. J. Therm. Sci., vol. 81, pp. 94-105, 2014.

Yang, X.H., Tan, S.C., and Liu, J., Numerical Investigation of the Phase Change Process of Low Melting Point Metal, Int. J. Heat Mass Transf., vol. 100, pp. 899-907, 2016.

Zhang, X.D., Gao, J.Y., Zhang, P.J., and Liu, J., Comparison on Enhanced Phase Change Heat Transfer of Low Melting Point Metal Melting Using Different Heating Methods, J. Enhanced Heat Transf., vol. 26, pp. 179-194, 2019.

Zhao, C.Y., Lu, W., and Tian, Y., Heat Transfer Enhancement for Thermal Energy Storage Using Metal Foams Embedded Within Phase Change Materials (PCMs), Solar Energy, vol. 84, pp. 1402-1412, 2010. 